\title{
Real-Time Seismic Monitoring of Instrumented Hospital Buildings
}

\section{The Veterans Affairs Medical Center in Memphis has been recently instrumented for real-time seismic monitoring}

n collaboration with the
Department of Veterans Affairs
(VA), the U.S. Geological Survey's
National Strong Motion Project has
recently installed sophisticated
seismic monitoring systems to
monitor the structural health of
two hospital buildings at the
Memphis VA Medical Center in
Tennessee. The monitoring systems
in the Bed Tower and Spinal Cord
Injury buildings combine sensing
technologies with an on-site
computer to capture and analyze
seismic performance of buildings
in near-real time.

The U.S. Geological Survey's (USGS) National Strong Motion Project (NSMP), a part of the Advanced National Seismic System (ANSS), has instrumented more than 250 structures in the continental United States, Alaska, Hawaii, and Puerto Rico for seismic monitoring. Installation of seismic monitoring systems in structures is part of the research program conducted under the National Earthquake Hazards Reduction Program (NEHRP) to improve understanding of the seismic loads that structures are likely to experience and help engineers design earthquake-resistant structures.

The NSMP works closely with VA to monitor earthquake shaking in more than 70 VA medical centers across the country. This effort not only helps the VA safeguard its building inventory from future earthquake losses but also ensures timely response to damaging earthquakes.

\section{Earthquake Risk in the New Madrid Seismic Zone}

The New Madrid Seismic Zone (NMSZ), which lies mainly in southeastern Missouri and northwestern Arkansas, is the most active seismic zone in the eastern United States. Today, the

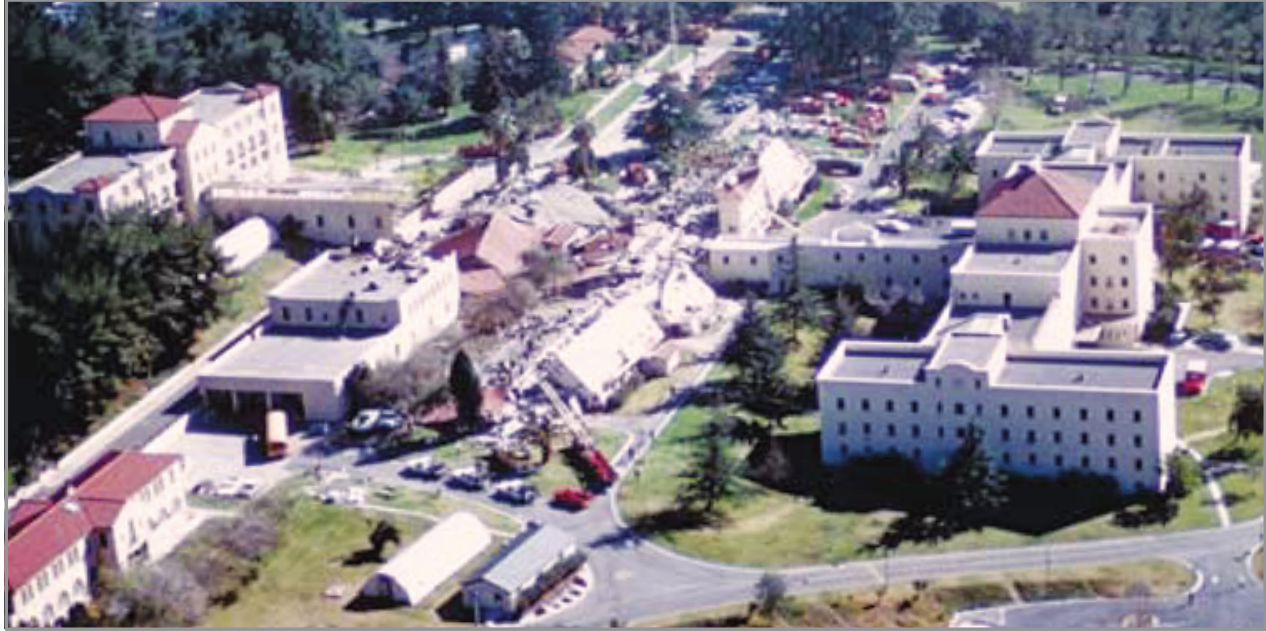

The 1971 San Fernando, California, earthquake (magnitude 6.7) collapsed four buildings at the San Fernando VA Hospital, killing 49 people. The buildings had been built in 1925, before building codes were in effect. Real-time seismic monitoring of such buildings can provide critical information about their structural integrity and help save lives in future earthquakes.

dense urbanization in the area increases earthquake risk-Memphis, Tenn. and St. Louis, Mo., are the largest vulnerable urban centers and sit well within range of damaging earthquakes in the NMSZ. This zone is well known for a series of major earthquakes during 1811-12. The geological record of pre-1811 earthquakes also reveals that the NMSZ has repeatedly produced sequences of major quakes, including several of magnitude 7 to 8 , over

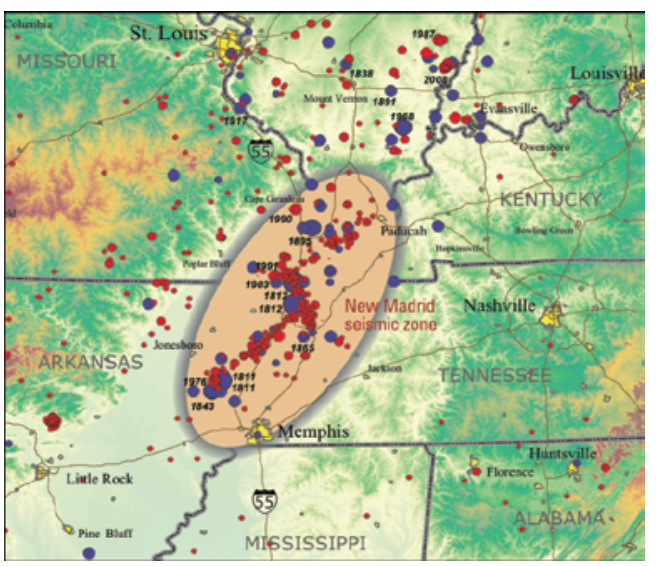

Map showing earthquakes greater than magnitude 2.5 in the New Madrid Seismic Zone and its surroundings. Red dots are earthquakes that occurred after 1972, blue dots are earthquakes before 1972. Magnitudes of earthquakes are proportional to size of dots-largest dots are magnitude 7-8. the past 4,500 years. These shocks caused severe and widespread ground failures in the New Madrid region, much like those caused by the 1811-12 earthquake sequence. A continuing concern exists for future major destructive earthquakes in the NMSZ. Many structures in Memphis, St. Louis, and other communities in the central Mississippi River Valley region are vulnerable and at risk from severe ground shaking. Such high hazard requires prudent measures to protect public safety and ensure the social and economic resilience of the region in future earthquakes. Seismic monitoring of structures is one of the urgent measures in preparing for those quakes.

\section{USGS Structural Health Monitoring}

The Nation's critical infrastructure includes hospitals, fire stations, emergency operation centers, major bridges, nuclear power plants, offshore platforms, and airports. It is imperative to monitor the condition of these structures in near-real time in order to be able to assess their structural integrity immediately after a major catastrophic event. Such efforts can help protect human lives and prevent 


\section{The USGS National Strong Motion Project Monitors Seismic Performance of Buildings at the Memphis VA Medical Center}

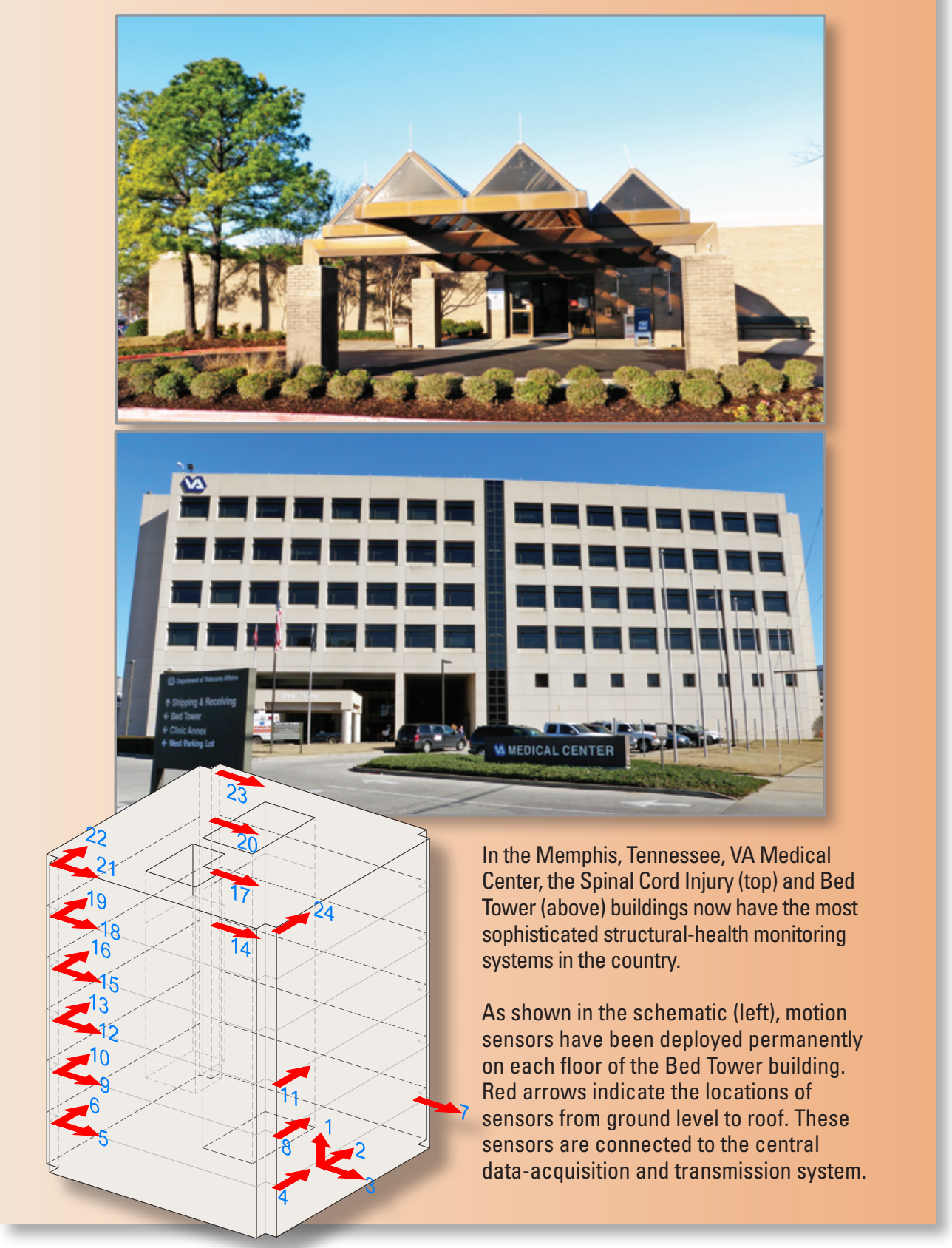

injuries, minimize economic losses (structural and nonstructural damage), maintain vital services, minimize operation/production interruptions, and protect the environment.

For these purposes, the USGS's NSMP has recently instrumented two buildings in the Memphis VA Medical Center. The monitoring system installed in the 5-story Bed Tower consists of a seismic array of 24 sensors. The 3-story Spinal Cord Injury building has 12 sensors. These sensors are deployed permanently in critical locations at each level of the buildings to detect building motion along the reference east-west and north-south directions; level. Specifically, the instrumentation within these buildings is designed to record lateral swaying, twisting (torsion), traveltime of transmitted seismic waves from foundation to roof, and drift (relative displacement) between pairs of adjacent floors, as well as overall building offset. The extent of swaying, twisting, and drift can be compared to what the building was designed to withstand.

The building sensors are complemented by three-component seismic sensors located at a reference site distant from the buildings to monitor ground shaking without interference from the vertical motion is monitored at the ground response of buildings. The sensors at the reference site measure the input seismic waves and feed USGS ShakeMaps, an online product that provides near-real-time maps of ground motion and shaking intensity following significant earthquakes. This dense array of seismic sensors in buildings and reference site is the main component of a sophisticated structural-health monitoring system at the Memphis VA Medical Center.

Recordings from such USGS structural-health monitoring systems are critical both to designing safer hospitals and other buildings and to preventing loss of life. In particular they will help engineers to:

- Understand how damage to structural and nonstructural components (such as equipment and pipes) occurs from strong shaking,

- Evaluate and improve earthquakeresistant design techniques and also methods for predicting the seismic performance of structures,

- Improve earthquake resistant design provisions of building codes, and

- Assess building safety immediately following a damaging quake.

\section{Erol Kalkan ${ }^{l}$, Jon Peter B. Fletcher ${ }^{l}$ William S. Leith ${ }^{2}$, Jill McCarthy, and Krishna Banga ${ }^{4}$}

${ }^{1}$ U.S. Geological Survey, Menlo Park, CA

${ }^{2}$ U.S. Geological Survey, Reston, VA

${ }^{3}$ U.S. Geological Survey, Golden, CO

${ }^{4}$ U.S. Department of Veternas Affairs, Washington, DC

Edited by Peter H. Stauffer

Graphic design by Jeanne S. DiLeo

COOPERATING ORGANIZATIONS

Advanced National Seismic System

U.S. Department of Veterans Affairs

\section{For more information, contact:}

Earthquake Science Center U.S. Geological Survey

Menlo Park, CA 94025

http://earthquake.usgs.gov/

Earthquake Information Hotline: (650) 329-4085

\section{Advanced National Seismic System http://www.anss.org/}

This Fact Sheet and any updates to it are available online at:

http://pubs.usgs.gov/fs/2012/3028/ 